\title{
Essential roles of the Fas-Fas ligand pathway in the development of pulmonary fibrosis
}

\author{
Kazuyoshi Kuwano, ${ }^{1}$ Naoki Hagimoto, ${ }^{1}$ Masayuki Kawasaki, ${ }^{1}$ Takehiro Yatomi, ${ }^{2}$ \\ Norio Nakamura, ${ }^{2}$ Shigekazu Nagata, ${ }^{3}$ Takashi Suda, ${ }^{4}$ Ritsuko Kunitake, ${ }^{1}$ \\ Takashige Maeyama, ${ }^{1}$ Hiroyuki Miyazaki, ${ }^{1}$ and Nobuyuki Hara ${ }^{1}$
}

${ }^{1}$ Research Institute for Diseases of the Chest, Faculty of Medicine, Kyushu University, Fukuoka 812-8582, Japan
${ }^{2}$ Biosciences Research Laboratory, Mochida Pharmaceutical Company, Tokyo 115-8515, Japan
${ }^{3}$ Department of Genetics, Osaka University Medical School B3, Osaka 565-0871, Japan
${ }^{4}$ Center for the Development of Molecular Target Drugs, Cancer Research Institute, Kanazawa
University, Kanazawa 920-0934, Japan

Address correspondence to: Kazuyoshi Kuwano, Research Institute for Diseases of the Chest, Faculty of Medicine, Kyushu University, 3-1-1, Maidashi, Higashiku, Fukuoka 812-8582, Japan. Phone: 81-92-642-5378;

Fax: 81-92-642-5389; E-mail: kkuwano@kokyu.med.kyushu-u.ac.jp.

Kazuyoshi Kuwano and Naoki Hagimoto contributed equally to this work.

Received for publication October 27, 1998, and accepted in revised form May 20, 1999.

\begin{abstract}
The Fas ligand is predominantly expressed in activated $\mathrm{T}$ lymphocytes and is one of the major effector molecules of cytotoxic T lymphocytes and natural killer cells. Previously, we found excessive apoptosis of epithelial cells and infiltrating lymphocytes expressing Fas ligand mRNA in the lung tissue of bleomycin-induced pulmonary fibrosis in mice. Here we demonstrated that the administration of a soluble form of Fas antigen or anti-Fas ligand antibody prevented the development of this model and that $l p r$ and $g l d$ mice were resistant against the induction of pneumopathy. These results suggest that the Fas-Fas ligand pathway plays an essential role in the development of pulmonary fibrosis and that preventing this pathway could have therapeutic value in lung injury and fibrosis.
\end{abstract}

J. Clin. Invest. 104:13-19 (1999).

\section{Introduction}

Fas antigen (Fas) is a member of the TNF receptor family and is expressed in various cells and tissues (1). Fas ligand (FasL), a cell surface molecule belonging to the TNF family, binds to its receptor Fas, thus inducing apoptosis of Fas-bearing cells. FasL is expressed predominantly in activated T lymphocytes and natural killer cells (2). FasL is one of the major effector molecules of cytotoxic $\mathrm{T}$ lymphocytes such as $\mathrm{CD}^{+} \mathrm{T}$ cells and $\mathrm{CD}^{+} \mathrm{T}$-helper 1 -type $\mathrm{T}$ cells (3-5). In the immune system, Fas and FasL are involved in downregulation of immune reactions (6-8). Malfunction of the FasFasL pathway causes lymphoproliferative disorders (9, $10)$, whereas its exacerbation may cause tissue destruction $(11,12)$.

Apoptosis may have a role in human diseases in 2 different ways. First, diseases may be caused by a malfunction of the apoptosis mechanism. Repair after an acute lung injury requires the elimination of proliferating mesenchymal and inflammatory cells from the alveolar air space or alveolar walls (13). Failure to clear unwanted cells by apoptosis will prolong the inflammation because of the release of their toxic contents. Second, excessive apoptosis may cause diseases. An intraperitoneal injection of agonistic anti-Fas antibody into adult mice caused hepatic failure and death, suggesting that acute fulminant hepatitis in humans may be caused by excessive apoptosis mediated by the Fas-FasL system (11).
Idiopathic pulmonary fibrosis (IPF) has an aggressive course and is usually fatal 3-6 years, on average, after the onset of symptoms. Patients commonly manifest dyspnea on exertion, cough, or both. Although the etiology is unknown, it is thought that IPF begins with alveolitis. As the disease continues, the inflammation persists and there is a gradual loss of normal lung parenchyma and interstitial fibrosis $(14,15)$. Previously we demonstrated that there was DNA damage or apoptosis in bronchiolar and alveolar epithelial cells in IPF, using the TUNEL method (16). Damage to and apoptosis of epithelial cells in acute lung injury were also demonstrated $(17,18)$. Furthermore, we found upregulation of Fas and FasL expression in bronchiolar and alveolar epithelial cells and in infiltrating lymphocytes or granulocytes, respectively, in lung tissue from patients with IPF (19).

The acute pulmonary toxicity induced by bleomycin in vivo includes DNA damage (20), which is known to induce apoptosis in vitro $(21,22)$. Bleomycin-induced pulmonary fibrosis is an animal model for IPF. In this model, FasL mRNA was upregulated in infiltrating lymphocytes, and Fas was upregulated in bronchiolar and alveolar epithelial cells in which excessive apoptosis was detected (23). We also demonstrated that the repeated inhalation of anti-Fas antibody mimicking Fas-FasL cross-linking induced excessive apoptosis of epithelial cells and inflammation, which resulted in pulmonary fibrosis in mice (24). 

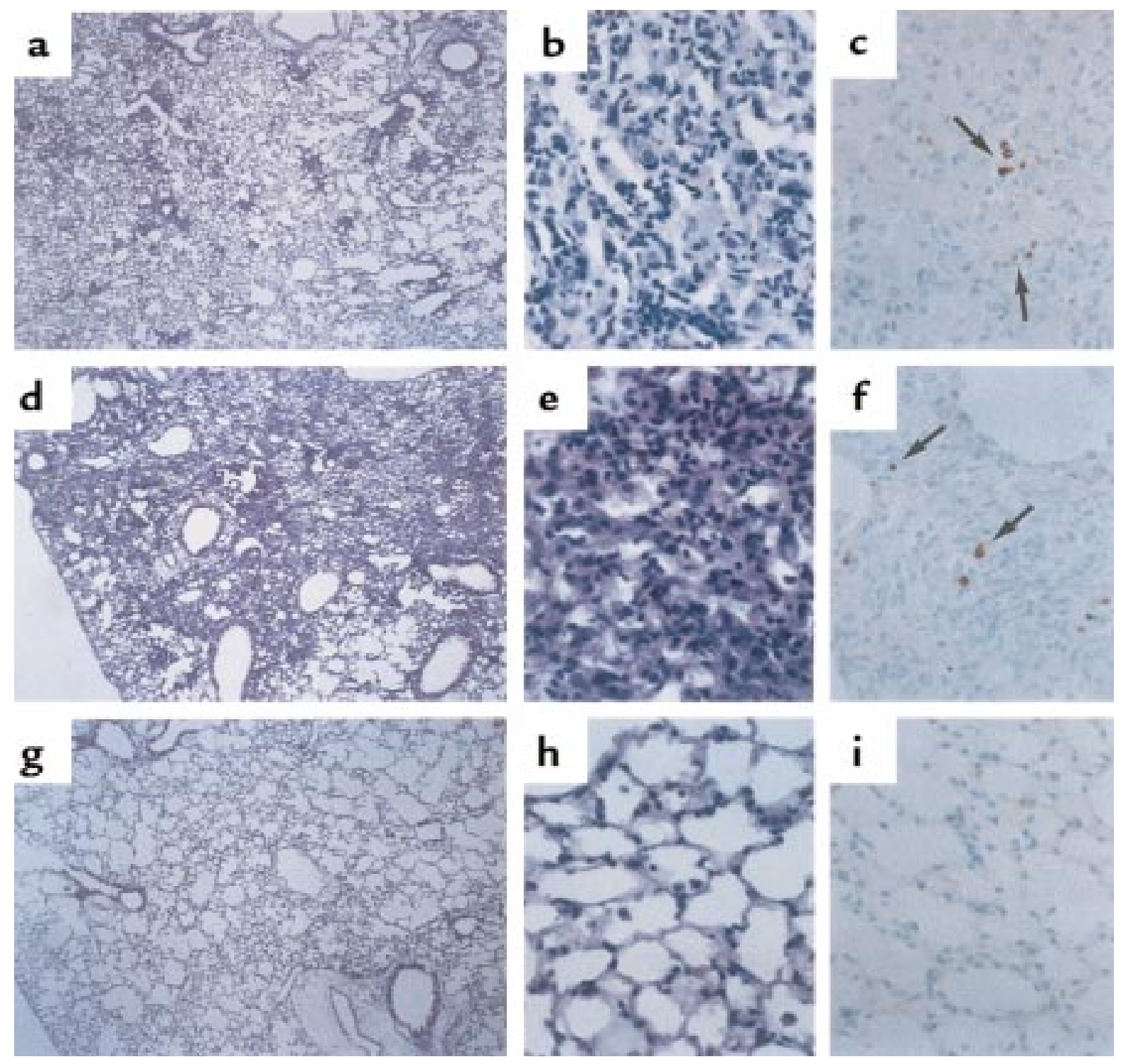

\section{Figure 1}

The effect of hFas-Fc on the microscopic findings of the murine lungs after bleomycin instillation. (a) Thickened alveolar septa are infiltrated with neutrophils and lymphocytes at day 7 after the bleomycin instillation. (b) Higher magnification of a septa stained with hematoxylin and eosin. (c) TUNEL-positive cells in serial section (arrow). (d) Marked thickening of the alveolar septa, collapse of alveolar spaces, a large number of lymphocytes accumulated in alveolar walls, and proliferation of the fibroblast at day 14 after the bleomycin instillation are seen. (e) Higher magnification of $\mathbf{d}$. ( $\mathbf{f}$ ) TUNEL-positive cells in serial section (arrow). Pathological changes ( $\mathbf{g}$ and $\mathbf{h}$ ) and positive signals for TUNEL (i) at day 14 were abrogated by injection of hFas-Fc at day 10 after bleomycin instillation. $\times 12.5$ (a, d, and $\mathbf{g}) ; \times 125(\mathbf{b}, \mathbf{c}, \mathbf{e}, \mathbf{f}, \mathbf{h}$, and $\mathbf{i})$.

In this study, we found that the administration of a soluble form of Fas (hFas-Fc) prevented apoptosis of epithelial cells and subsequent development of fibrosis in a mouse model of bleomycin-induced pulmonary fibrosis. We also demonstrated that anti-FasL antibody ameliorated pulmonary fibrosis in this model. Furthermore, C3H-lpr/lpr (lpr) and $\mathrm{C} 3 \mathrm{H}-$ gld/gld $(g l d)$ mice were resistant to the induction of this model. The $l p r$ and gld mutations are the loss of functional mutations of Fas and FasL, respectively (25). These results may indicate that excessive apoptosis induced by the Fas-FasL pathway is critical in the development of pulmonary fibrosis and the development of a possible therapeutic use for molecules that prevent the Fas-FasL pathway in patients with lung injury and pulmonary fibrosis.

\section{Methods}

Preparation of $b F a s-F c$ and anti-FasL antibody. As described previously (26), hFas-Fc was prepared by expressing the hybrid gene consisting of the extracellular region of human Fas fused to the Fc region of the human immunoglobulin heavy chain. After purification with protein A-Sepharose, hFas-Fc was administered to mice to examine its inhibitory effects, according to the protocols shown in Table 1. The antagonistic anti-FasL antibody was the same antibody used by Miwa et al. (27). 
Table 1

hFas-Fc study design

\begin{tabular}{|c|c|c|}
\hline Group & Bleomycin treatment & hFas-Fc administration \\
\hline \multicolumn{3}{|l|}{ hFas-Fc injection } \\
\hline BLM & Day 1 , it & NA \\
\hline BLM + IgG iv day 7 & Day 1 , it & Day $7,50 \mu \mathrm{g}$ human IgG/body, iv \\
\hline BLM + Fas iv day 1 & Day 1 , it & Day $1,50 \mu \mathrm{g} /$ body, iv \\
\hline BLM + Fas iv day 7 & Day 1 , it & Day $7,50 \mu \mathrm{g} /$ body, iv \\
\hline BLM + Fas iv day 10 & Day 1 , it & Day $10,50 \mu \mathrm{g} /$ body, iv \\
\hline \multicolumn{3}{|l|}{ hFas-Fc inhalation } \\
\hline$B L M+\lg G$ inh & Day 1 , it & Days $2,4,6,8,10$, and $12 ; 50 \mu \mathrm{g}$ human $\operatorname{lgG}$, USN \\
\hline BLM + Fas inh & Day 1 , it & Days $2,4,6,8,10$, and $12 ; 5 \mu \mathrm{g} / \mathrm{mL}$, USN \\
\hline BLM + Fas inh & Day 1 , it & Days $2,4,6,8,10$, and $12 ; 50 \mu \mathrm{g} / \mathrm{mL}$, USN \\
\hline Fas inh & NT & Days $2,4,6,8,10$, and $12 ; 50 \mu \mathrm{g} / \mathrm{mL}$, USN \\
\hline
\end{tabular}

BLM, bleomycin; Fas, hFas-Fc; it, intratracheal instillation; iv, intravenous injection; NA, no administration; NT, no treatment; USN, ultrasonic nebulizer; inh, inhalation by USN.

Histological evaluation. After sacrifice, the right lung tissues were fixed by inflation with buffered $10 \%$ formalin solution for 24 hours. After embedding in paraffin, 3 sections per sample were cut in 3- $\mu \mathrm{m}$ thicknesses and stained with hematoxylin and eosin. The sections for each mouse were composed of 3 sagittal sections obtained at 1-mm intervals extending from the apex to the base of the right lung tissues. The pathological grades of inflammation and fibrosis in whole areas of each section were evaluated by a pathologist (H. Miyazaki) who did not know the treatment program, using $\times 40$ light microscopy. A

Model of bleomycin-induced pulmonary fibrosis in mice. Sixweek-old ICR mice were used in the study of hFas-Fc. Following measurement of their body weight, the animals were anesthetized with an intraperitoneal injection of sodium pentobarbital (Dinabot Co., Osaka, Japan). The body weight of each mouse was almost $30 \mathrm{~g}$. The anesthetized animals received an intratracheal injection of $50 \mu \mathrm{L}$ of a bleomycin hydrochloride (Nippon Kayaku Co., Tokyo, Japan) solution containing $4 \mathrm{mg}$ of bleomycin dissolved in a sterile saline solution per kilogram of body weight. In these experiments, the animals were divided into 9 groups (Table 1 ). Mice of group 1 were treated with the bleomycin solution. Mice of groups $2-5$ were treated with bleomycin and intravenously injected with $50 \mu \mathrm{g} /$ body human $\operatorname{IgG}$ at day 7 and $50 \mu \mathrm{g} /$ body hFas-Fc at day 1 , day 7 , or day 10 , respectively. Mice of groups 6-8 were treated with bleomycin, put in a chamber, and allowed to inhale $10 \mathrm{~mL}$ of an aerosolized $50 \mu \mathrm{g} / \mathrm{mL}$ human IgG, $5 \mu \mathrm{g} / \mathrm{mL}$ hFas-Fc, or $50 \mu \mathrm{g} / \mathrm{mL}$ hFas-Fc, respectively, in saline, by ultrasonic nebulizer (USN) every other day from days 2-12. Mice of group 9 inhaled $50 \mu \mathrm{g} / \mathrm{mL}$ hFas-Fc without bleomycin instillation every other day from days $2-12$. After recovery from anesthesia, mice were returned to their cages and allowed food and water ad libitum. Mice were anesthetized with ether at days 7 and 14 after the bleomycin instillation, and then sacrificed. After thoracotomy, the pulmonary circulation was flushed with saline, and the lungs were explored. The right lung tissues were excised and processed for light microscopy. The left lung tissues were frozen in liquid nitrogen to measure hydroxyproline content. Six-week-old ICR mice were used in the study of anti-FasL antibody. Anti-FasL antibody was intravenously injected at day 7 after bleomycin instillation. Mice were sacrificed and lung tissues were excised at day 14 , as described above.

Six-week-old wild-type $\mathrm{C} 3 \mathrm{H} l p r$ and gld mice were used. The body weight of each mouse was almost $20 \mathrm{~g}$. Mice were sacrificed and lung tissues were excised at days 7 and 14 after bleomycin instillation, as described above. pathological grade for each lung section was determined according to the following criteria: $0=$ no lung abnormality; 1 = presence of inflammation and fibrosis involving $<25 \%$ of the lung parenchyma; $2=$ lesions involving $25-50 \%$ of the lung; 3 = lesions involving $>50 \%$ of the lung. The mean of the pathological grade for 3 sections was individually determined for each mouse.

Quantification of apoptosis in lung tissues by TUNEL. Terminal deoxynucleotidyl transferase-mediated dUTP nick end labeling (TUNEL) was performed using the In Situ Apoptosis Detection Kit (Takara, Ohtsu, Japan) according to the manufacturer's protocols. As in the histological evaluation, the sections examined by TUNEL for each mouse were composed of 3 sagittal sections obtained at $1-\mathrm{mm}$ intervals, extending from the apex to the base of the right lung tissues. The mean of the numbers of TUNEL-positive cells for 3 sections was individually determined for each mouse. Three mice per group were examined. The number of positive signals in whole areas of each section was evaluated by a pathologist (H. Miyazaki) who did not know the treatment, using $\times 400$ light microscopy.

Hydroxyproline assay. The left lung tissues obtained from mice were assayed using hydroxyproline. The lungs were frozen in liquid nitrogen, lyophilized by a freeze-dry system (Labconco, Kansas City, Missouri, USA), weighted, and minced into a fine homogenous mixture. The lung tissue was hydrolyzed in $6 \mathrm{~N} \mathrm{HCl}$ for 16 hours at $120^{\circ} \mathrm{C}$. The hydroxyproline content of each sample was determined according to the protocols of Woessner (28).

Statistical analysis. To determine statistical significance, the pathological grades were compared using the Mann-Whitney $U$ test with Statview J4.11 software(Abacus Concepts Inc., Berkeley, California, USA). The number of TUNEL-positive cells and the hydroxyproline content were compared using Student's $t$ test with the Microsoft Exel Version 5.0a package (Microsoft Corp., Bellevue, Washington, USA). $P$ values less than 0.05 were considered significant. 
Table 2

Effect of hFas-Fc on histological evaluation

\begin{tabular}{lcc} 
& \multicolumn{2}{c}{ Pathological grade $(\text { mean } \pm \text { SD })^{\mathrm{A}}$} \\
Group & Day 7 & Day 14 \\
hFas-Fc injection & & \\
BLM & $1.89 \pm 0.61(n=12)$ & $1.73 \pm 0.62(n=10)$ \\
BLM + IgG iv day 7 & - & $2.00 \pm 1.00(n=3)$ \\
BLM + Fas iv day 1 & $1.45 \pm 0.54(n=6)$ & $2.45 \pm 0.89(n=6)$ \\
BLM + Fas iv day 7 & - & $0.33 \pm 0.47(n=8)^{\mathrm{B}}$ \\
BLM + Fas iv day 10 & - & $0.08 \pm 0.17(n=4)^{\mathrm{B}}$ \\
hFas-Fc inhalation & & \\
BLM + IgG inh & $2.08 \pm 0.74(n=4)$ & $2.67 \pm 0.58(n=3)$ \\
BLM + Fas inh $(5 \mu \mathrm{g} / \mathrm{mL})$ & $2.00 \pm 0.21(n=6)$ & $2.30 \pm 0.61(n=9)$ \\
BLM + Fas inh $(50 \mu \mathrm{g} / \mathrm{mL})$ & $1.67 \pm 0.55(n=7)$ & $0.92 \pm 1.00(n=8)^{\mathrm{C}}$ \\
Fas inh $(50 \mu \mathrm{g} / \mathrm{mL})$ & $0.00 \pm 0.00(n=10)^{\mathrm{D}}$ & $0.03 \pm 0.10(n=10)^{\mathrm{D}}$
\end{tabular}

APathological grade: $0=$ no abnormality; $1=$ affected lesion $<25 \% ; 2=25-50 \% ; 3=$ $>50 \%$. ${ }^{\mathrm{B}}<\mathrm{BLM}, \mathrm{BLM}+\operatorname{lgG}$ iv day $7 ; P<0.05$. ${ }^{\mathrm{C}}<\mathrm{BLM}, \mathrm{BLM}+\lg \mathrm{G}$ inh; $P<0.05$. D $<$ BLM, BLM + IgG inh; $P<0.01$.

\section{Results}

The effect of hFas-Fc on histological evaluation. To investigate the role of Fas-FasL interaction in the development of bleomycin-induced pulmonary fibrosis, we used hFas$\mathrm{Fc}$ in which the extracellular region of human Fas is fused to human IgG. The amino acid sequence of human and mouse FasL is well conserved, and hFas-Fc can efficiently neutralize mouse FasL (29). As shown in Table 1, hFas-Fc was administered through 2 routes: intravenous injection or inhalation by USN.

Figure 1 shows a representative histological sample in this model. At 7 days after the bleomycin administration, the alveolar wall was beginning to thicken, with infiltration of neutrophils and lymphocytes (Figure 1, $\mathrm{a}$ and $\mathrm{b}$ ). After 14 days, a large number of lymphocytes infiltrated into the lung interstitium, and thickening of the alveolar septa, collapse of alveolar spaces, and proliferation of fibroblasts were observed (Figure 1, d and e). Intravenous injection of $50 \mu \mathrm{g} /$ body hFas-Fc at day 7 or 10 (Figure 1, g and h), or inhalation of 50 $\mu \mathrm{g} / \mathrm{mL}$ hFas-Fc after bleomycin instillation, abrogated the inflammatory cell infiltration and fibrosis in lung tissues at day 14 .

Table 2 shows the results of histological evaluation. The pathological grade at day 7 or 14 was not affected by intravenous injection of hFas-Fc at day 1 . However, intravenous injection of hFas-Fc at day 7 or 10 after bleomycin instillation ameliorated the pathological grade at day 14 compared with mice treated with bleomycin alone $(P<0.05)$ or with human IgG injection instead of hFas-Fc $(P<0.05)$.

The inhalation of $50 \mu \mathrm{g} / \mathrm{mL}$ hFas-Fc did not ameliorate the pathological grade at day 7 after bleomycin instillation. However, it significantly decreased the pathological grade at day 14 compared with mice treated with human $\operatorname{IgG}(P<0.05)$ or bleomycin alone $(P<$ $0.05)$. The inhalation of $5 \mu \mathrm{g} / \mathrm{mL}$ hFas-Fc did not ameliorate the pathological grade at day 7 or 14 after bleomycin instillation.
The effect of hFas-Fc on the results of TUNEL. Although the type of cells was not clearly identified, some bronchiolar and alveolar epithelial cells or inflammatory cells in inflammatory lesions showed evidence of apoptosis, as estimated by the TUNEL method, at days 7 and 14 after bleomycin instillation (Figure 1, c and f, respectively). Positive signals for TUNEL at day 14 were decreased in lung tissue of mice treated with intravenous injection of hFas-Fc at day 7 or 10 (Figure 1i) or with inhalation of $50 \mu \mathrm{g} / \mathrm{mL}$ hFas-Fc after bleomycin instillation.

Table 3 shows the results of TUNEL. The number of TUNEL-positive signals at day 7, but not day 14 , was significantly decreased in mice injected with $50 \mu \mathrm{g} / \mathrm{mL}$ hFas-Fc at day 1 after bleomycin instillation compared with mice treated with bleomycin alone $(P<0.01)$. The number of TUNEL-positive cells at day 14 was significantly decreased in lung tissues of mice treated with intravenous injection of $50 \mu \mathrm{g} /$ body hFas-Fc at day 7 or $10(P<0.01)$, and in mice treated with inhalation of $50 \mu \mathrm{g} / \mathrm{mL}$ hFas-Fc after bleomycin instillation $(P<$ $0.01)$, compared with mice treated with bleomycin alone or with those that received injected or inhaled human IgG instead of hFas-Fc. The inhalation of 5 $\mu \mathrm{g} / \mathrm{mL}$ hFas-Fc after bleomycin instillation did not decrease the number of TUNEL-positive cells at either day 7 or day 14.

The effect of hFas-Fc on lung bydroxyproline content. Table 4 shows the effect of hFas-Fc on hydroxyproline content on lung tissues, which represents the extent of fibrosis, at day 14 after bleomycin instillation. There was a significant increase in lung hydroxyproline content in mice at day 14 after bleomycin instillation compared with mice that inhaled hFas-Fc alone $(P<0.05)$. There was a significant decrease in lung hydroxyproline content in mice treated with intravenous injection of $50 \mu \mathrm{g} /$ body hFas-Fc at day 7 or $10(P<0.05)$ and with inhalation of $50 \mu \mathrm{g} / \mathrm{mL}$ hFas-Fc $(P<0.05)$ after

\section{Table 3}

Effect of hFas-Fc on the number of TUNEL-positive cells in lung tissue

TUNEL-positive cells (per $\mathrm{mm}^{2}$, mean $\pm \mathrm{SD}$ )

$$
\text { Day } 7 \quad \text { Day } 14
$$

hFas-Fc injection

BLM

BLM $+\lg G$ iv day 7

BLM + Fas iv day 1

BLM + Fas iv day 7

$\mathrm{BLM}+$ Fas iv day 10

$\begin{array}{cc} & \\ 7.15 \pm 1.37 & 8.63 \pm 0.46 \\ - & 5.45 \pm 0.94 \\ 1.65 \pm 0.60^{\mathrm{A}} & 5.55 \pm 1.40 \\ - & 1.97 \pm 1.76^{\mathrm{B}} \\ - & 0.39 \pm 0.24^{\mathrm{B}}\end{array}$

hFas-Fc inhalation

BLM + IgG inh

BLM + Fas inh $(5 \mu \mathrm{g} / \mathrm{mL})$

BLM + Fas inh $(50 \mu \mathrm{g} / \mathrm{mL})$

$7.03 \pm 1.40$

$10.1 \pm 1.59$

$5.17 \pm 0.73 \quad 7.81 \pm 3.48$

$\begin{array}{ll}3.92 \pm 2.23 & 1.68 \pm 0.63 \mathrm{C} \\ 0.03 \pm 0.06 \mathrm{C} & 0.03 \pm 0.06 \mathrm{C}\end{array}$

Fasinh $(50 \mu \mathrm{g} / \mathrm{mL}) \quad 0.03 \pm 0.06^{\mathrm{C}} \quad 0.03 \pm 0.06^{\mathrm{C}}$

$\mathrm{A}<\mathrm{BLM} ; \mathrm{P}<0.01 .{ }^{\mathrm{B}}<\mathrm{BLM}, \mathrm{BLM}+\lg \mathrm{g}$ iv day $7 ; \mathrm{P}<0.01 . \mathrm{C}^{\mathrm{C}}<\mathrm{BLM}, \mathrm{BLM}+\lg \mathrm{G}$ inh; $P<0.01$. Three mice per group were examined. 
Table 4

Effect of hFas-Fc on hydroxyproline content in lung tissue

Hydroxyproline $(\mu \mathrm{g} / \mathrm{mg}$ of lung, mean $\pm \mathrm{SD})$

hFas-Fc injection

$\begin{array}{lc}\text { BLM } & 56.1 \pm 6.7 \\ \text { BLM + IgG iv day 7 } & 82.6 \pm 25.9 \\ \text { BLM + Fas iv day } 1 & 50.6 \pm 7.4 \\ \text { BLM + Fas iv day } 7 & 14.6 \pm 18.1^{\mathrm{A}} \\ \text { BLM + Fas iv day } 10 & 17.2 \pm 13.0^{\mathrm{A}} \\ \text { Saline it } & 15.3 \pm 3.7^{-} \\ \text {hFas-Fc inhalation } & \\ \text { BLM + IgG inh } & 69.9 \pm 26.4 \\ \text { BLM + Fas inh }(5 \mu \mathrm{g} / \mathrm{mL}) & 83.5 \pm 24.3 \\ \text { BLM + Fas inh }(50 \mu \mathrm{g} / \mathrm{mL}) & 13.7 \pm 20.7^{\mathrm{B}} \\ \text { Fas inh }(50 \mu \mathrm{g} / \mathrm{mL}) & 12.7 \pm 16.1^{\mathrm{B}}\end{array}$

${ }^{\mathrm{A}}<\mathrm{BLM}, \mathrm{BLM}+\lg \mathrm{g}$ iv day $7 ; P<0.05 .{ }^{\mathrm{B}}<\mathrm{BLM}, \mathrm{BLM}+\lg \mathrm{G}$ inh; $P<0.05$. Three mice per group were examined.

bleomycin instillation, compared with that in mice treated with bleomycin alone or with human IgG injection or inhalation instead of hFas-Fc. The intravenous injection of $50 \mu \mathrm{g} /$ body hFas-Fc at day 1 or the inhalation of $5 \mu \mathrm{g} / \mathrm{mL}$ hFas-Fc did not decrease hydroxyproline content in lung tissues.

The effect of anti-FasL antibody on bleomycin-induced pulmonary fibrosis. We also examined the effect of anti-FasL antibody on this model. We injected anti-FasL antibody at day 7 after bleomycin instillation, according to the results of a study using hFas-Fc. There was a significant decrease in the pathological grade at day 14 for mice injected with anti-FasL antibody $(0.90 \pm 0.99)$ compared with mice treated with nonimmune hamster IgG instead $(2.38 \pm 0.92)(\mathrm{P}<0.01)$.

Bleomycin-induced pulmonary fibrosis in lpr and gld mice. To confirm the significance of the Fas-FasL pathway, we investigated the development of this model in lpr and gld mice. There was a significant decrease in the pathological grade, the number of TUNEL-positive cells at days 7 and 14, and the hydroxyproline content at day 14 after bleomycin instillation in $l p r$ and gld mice compared with wild-type mice (Table 5). In addition, lpr and gld mice all survived, whereas 4 of 10 wild-type $\mathrm{C} 3 \mathrm{H}$ mice were dead before day 14 after bleomycin instillation.

\section{Discussion}

The pathological grades at days 7 and 14 were not affected by the injection of hFas-Fc at day 1 . The injection of hFas-Fc at day 7 or 10 decreased the pathological grade at day 14 . The inhalation of $50 \mu \mathrm{g} / \mathrm{mL}$ hFasFc decreased the pathological grade at day 14 but not at day 7 . These results suggest that administration of hFas-Fc on days 7-14 was more effective than when done before day 7 and that the Fas-FasL pathway may have more important roles during the late period in the development of this model. Injection of anti-FasL antibody at day 7 also ameliorated the development of pulmonary fibrosis. Furthermore, the finding that $l p r$ and gld mice were resistant to the induction of this model supported the hypothesis that the Fas-FasL pathway was involved in its pathophysiology.

Because the Fas-FasL pathway is associated with apoptosis, we have assessed the degree of apoptotic cell death using the TUNEL method. TUNEL-positive cells were detected primarily in the core of the inflammatory lesion. Although the type of cells that stained positive using TUNEL was not clearly identified, we demonstrated previously the apoptosis of bronchiolar and alveolar epithelial cells using electron microscopy in this model (23). The number of positive cells at day 14 was significantly decreased by the injection of hFas$\mathrm{Fc}$ at day 7 or 10 and by inhalation of $50 \mu \mathrm{g} / \mathrm{mL}$ hFasFc. These results were consistent with those of the pathological grade.

The hydroxyproline content in lung tissue was significantly decreased by injection of hFas-Fc at day 7 or 10 and by inhalation of $50 \mu \mathrm{g} / \mathrm{mL}$ hFas-Fc. It was not decreased by the injection of hFas-Fc at day 1 . These results were consistent with those gained by histological evaluation and TUNEL and suggested that the inhibition of apoptosis induced by the Fas-FasL pathway from days 7-14 may be of primary importance in preventing pulmonary fibrosis in this model.

Table 5 shows that the number of TUNEL-positive cells and the pathological grade at days 7 and 14 were significantly decreased in $l p r$ and gld mice compared with wild-type mice. Therefore, the Fas-FasL pathway seems to be important in the pathological grade and apoptosis in this model. However, as shown in Tables 2 and 3 , the number of TUNEL-positive cells, but not the pathological grade at day 7 , was significantly decreased by the injection of hFas-Fc at day 1 . This difference seems to be due to the fact that the blocking effect of hFas-Fc on the Fas-FasL pathway may not be as effective as the Fas or FasL deficiency, because hFas-Fc was injected at day 1 and the concentration of this molecule seemed to be decreased by day 5 , when the inflammatory cell infiltration began to occur (becoming predominant at days 7-14).

When hFas-Fc was given on day 7 or 10, apoptosis and the pathological grade at day 14 were significantly suppressed. However, much of the lymphocyte infiltration and lung injury has occurred at day 7 . Because excessive apoptosis and inflammatory cell infiltration induced by bleomycin were not resolved spontaneously until day 14, as shown by the pathological grade and the number of TUNEL-positive cells, we consider that the hFas-Fc administration at day 7 or 10 could ameliorate the pathological grade and apoptosis at day 14 .

It is possible that the mechanism by which hFas- $\mathrm{Fc}_{\mathrm{c}}$ ameliorated the pneumopathy may be partly the result of the anti-inflammatory effect. Seino et al. reported that FasL on tumor cells can induce a granulocytemediated rejection reaction. Tumors expressing FasL induced granulocyte infiltration, and the rejection was followed by a $\mathrm{T}$ cell-dependent anti-tumor immunity (30). Agonistic anti-Fas antibody administration can 
Table 5

Bleomycin-induced pulmonary fibrosis in $\mathrm{C} 3 \mathrm{H}-\mathrm{lpr}$ and $\mathrm{C} 3 \mathrm{H}-g / d$ mice

\begin{tabular}{|c|c|c|c|c|c|}
\hline & \multicolumn{2}{|c|}{$\begin{array}{l}\text { Pathological grade } \\
\quad(\text { mean } \pm S D)\end{array}$} & \multicolumn{2}{|c|}{$\begin{array}{l}\text { TUNEL-positive cells } \\
\left.\text { (per } \mathrm{mm}^{2}, \text { mean } \pm \mathrm{SD}\right)\end{array}$} & \multirow{2}{*}{$\begin{array}{c}\text { Hydroxyproline } \\
(\mu \mathrm{g} / \mathrm{mg} \text { of lung, mean } \pm \mathrm{SD}) \\
\text { Day } 14\end{array}$} \\
\hline & Day 7 & Day 14 & Day 7 & Day 14 & \\
\hline A. C3H-wild & $\begin{array}{c}2.11 \pm 0.31 \\
(n=9)\end{array}$ & $\begin{array}{c}2.67 \pm 0.62 \\
(n=6)\end{array}$ & $8.41 \pm 5.30$ & $3.03 \pm 1.54$ & $51.7 \pm 10.4$ \\
\hline B. $\mathrm{C} 3 \mathrm{H}-1 p r$ & $\begin{array}{c}1.00 \pm 0.87^{\mathrm{A}} \\
(n=9)\end{array}$ & $\begin{array}{c}0.70 \pm 1.00^{B} \\
(n=10)\end{array}$ & $0.87 \pm 1.50^{\mathrm{A}}$ & $0.50 \pm 0.19^{A}$ & $18.4 \pm 2.0^{\mathrm{A}}$ \\
\hline C. $\mathrm{C} 3 \mathrm{H}-\mathrm{gld}$ & $\begin{array}{c}1.22 \pm 0.22^{\mathrm{A}} \\
(n=9)\end{array}$ & $\begin{array}{c}0.80 \pm 0.47^{\mathrm{B}} \\
(n=10)\end{array}$ & $0.70 \pm 0.79^{A}$ & $0.20 \pm 0.11^{\mathrm{A}}$ & $20.2 \pm 1.9^{\mathrm{A}}$ \\
\hline
\end{tabular}

A Wild > [AUTHOR: please spell out what you intend by "Wild >"] $/ p r, g l d ; P<0.05 .{ }^{B}$ Wild $>[$ AUTHOR: spell out what you intend by "Wild $>$ "] $/ p r, g l d$; $P<0.01$. The scoring of pathological grade was described in Table 2. Five mice per group were examined in TUNEL and hydroxyproline assays.

lead to production of IL-8 more than TNF- $\alpha$ administration by colonic epithelial cells in vitro (31). We found the results to be the same in bronchiolar epithelial cells (N. Hagimoto et al., manuscript submitted for publication). These results implicate FasL in a role as a proinflammatory cytokine in the pathophysiology of pulmonary fibrosis. In our study, the administration of hFas-Fc or anti-FasL antibody may prevent the development of pneumopathy, not only because of the inhibition of apoptosis but also because FasL may play a role as a proinflammatory cytokine.

However, as shown in lpr and gld mice, the inflammatory cell infiltration to alveolar walls does not always mean alveolitis or lung injury and fibrosis. Autopsied $\mathrm{C} 3 \mathrm{H}-$ gld mice have extensive inflammatory diseases of the lung, resembling interstitial pneumonitis (32). Typically, a large number of well-differentiated lymphocytes and macrophages accumulate in the alveolar septa; this is also found in bleomycininduced pulmonary fibrosis in mice in this study. However, there are some differences between interstitial pneumonitis in mutant mice and bleomycininduced pneumonitis in wild-type mice. First, bronchiolitis and alveolitis, followed by epithelial cell apoptosis, occur in bleomycin-induced pulmonary fibrosis in mice, whereas neither alveolitis nor bronchiolitis is found in interstitial pneumonitis in mutant mice. Second, the alveoli are not collapsed in interstitial pneumonitis in mutant mice, whereas in bleomycin-induced pulmonary fibrosis they were collapsed, lost, and replaced by fibroblasts, and, subsequently, alveolar ducts and bronchioli became dilated. Therefore, the pathophysiology of interstitial pneumonitis in lpr and gld mice and that of bleomycininduced pulmonary fibrosis seem to be distinct in epithelial cell damage. The inflammatory cell infiltration into alveolar walls does not always mean alveolitis or lung injury. Some functional effectors, such as the Fas-FasL pathway, appear to be required to damage the tissues. As shown in Table 5, the Fas-FasL pathway is an important contributor to the pathological grade, apoptosis, and pulmonary fibrosis induced by bleomycin. Therefore, it is unlikely that the inflam- matory cell infiltration can induce pulmonary fibrosis without epithelial cell apoptosis, although the antiinflammatory effect of hFas-Fc may also play some role in this model.

Apoptosis induced by the Fas-FasL pathway is essential for the induction and/or progression of some organ-specific tissue injury. It was demonstrated that the Fas-FasL pathway plays a critical role in the development of autoimmune encephalomyelitis, because Fas- or FasL-deficient mice are resistant to the induction of this disorder $(33,34)$. In graft-versus-host disease, the ability of the graft effector cells to express functional FasL contributes to the tissue damage (35, 36). Agonistic anti-Fas antibody induces apoptosis in hepatocytes in vivo (11). We also demonstrated that inhalation of agonistic anti-Fas antibody induced pulmonary fibrosis in mice (24), and this has led to the idea that FasL-induced apoptosis of these cells contributes to some forms of pneumopathy. These results suggested that blocking the function of FasL is clearly a key to preventing tissue damage under a number of different circumstances.

We demonstrated here that apoptosis induced by the Fas-FasL pathway, probably in bronchiolar and alveolar epithelial cells, was involved in the development of pulmonary fibrosis in this model. We found that the expression of FasL was upregulated in infiltrating lymphocytes and granulocytes, while Fas was also upregulated in bronchiolar and alveolar epithelial cells in lung tissues of IPF (19). Excessive apoptosis and upregulation of FasL expression appear to be consistent in animal models of pulmonary fibrosis and in human diseases. Therefore, hFas-Fc, anti-FasL antibody, or inhibitors of the Fas-FasL pathway may prevent the progression of pulmonary fibrosis.

1. Itoh, N., et al. 1991. The polypeptide encoded by the cDNA for human cell surface antigen Fas can mediate apoptosis. Cell. 66:233-243.

2. Suda, T., Takahashi, T., Golstein, T., and Nagata, S. 1993. Molecular cloning and expression of the Fas ligand, a novel member of the tumor necrosis factor family. Cell. 75:1169-1178.

3. Suda, T., et al. 1995. Expression of the Fas ligand in cells of T-cell-lineage. J. Immunol. 154:3806-3813.

4. Lowin, B., Hahne, M., Mattmenn, C., and Tschopp, J. 1994. Cytotoxic Tcell cytotoxicity is mediated through perforin and Fas lytic pathways. Nature. 370:650-652. 
5. Kägi, D., et al. 1994. Fas and perforin pathways as major mechanisms of T-cell mediated cytotoxicity. Science. 265:528-530.

6. Dhein, J., Walczak, H., Bäumler, C., Debatin, K.M., and Krammer, P.H 1995. Autocrine T-cell suicide mediated by APO-1/(Fas/CD95). Nature. 373:438-441.

7. Brunner, T., et al. 1995. Cell-autonomous Fas(CD95)/Fas-ligand interaction mediates activation-induced apoptosis in T-cell hybridomas. Nature. 373:441-444.

8. Ju, S.T., et al. 1995. Fas(CD95)/FasL interactions required for programmed cell death after T-cell activation. Nature. 373:444-448.

9. Watanabe-Fukunaga, R., Brannan, C.I., Copeland, N.G., Jenkins, N.A., and Nagata, S. 1992. Lymphoproliferation disorder in mice explained by defects in Fas antigen that mediates apoptosis. Nature. 356:314-317.

10. Takahashi, T., et al. 1994. Generalized lymphoproliferative disease in mice, caused by a point mutation in the Fas ligand. Cell. 76:969-976.

11. Ogasawara, J., et al. 1993. Lethal effect of the anti-Fas antibody in mice. Nature. 364:806-809.

12. Hiramatsu, N., et al. 1994. Immunohistochemical detection of Fas antigen in liver tissue of patients with chronic hepatitis C. Hepatology. 19:1354-1359.

13. Polunovsky, V.A., et al. 1993. Role of mesenchymal cell death in lung remodeling after injury. J. Clin. Invest. 92:388-397.

14. Liebow, A. 1975. Definition and classification of interstitial pneumonia in human pathology. In Progress in respiration research. Volume 8. F. Baset and R. George, editors. S. Karger AG. Basel, Switzerland. New York, NY. $1-33$.

15. Crystal, R.G., et al. 1984. Interstitial lung diseases of unknown cause. I. Disorders characterized by chronic inflammation of the lower respiratory tract. N. Engl. J. Med. 310:154-166.

16. Kuwano, K., et al. 1996. p21 Waf1/Cip1 and $\mathrm{p} 53$ expression in association with DNA strand breaks in idiopathic pulmonary fibrosis. Am. J. Respir. Crit. Care Med. 154:477-483.

17. Guinee, D., et al. 1996. Association of p53 and WAF1 expression with apoptosis in diffuse alveolar damage. Am. J. Pathol. 149:531-538.

18. Bardales, R.H., Xie, S., Schaefer, R.F. and Hsu, S. 1996. Apoptosis is a major pathway responsible for the resolution of type II pneumocytes in acute lung injury. Am. J. Pathol. 149:845-852.

19. Kuwano, K., et al. 1999. The involvement of Fas-Fas ligand pathway in fibrosing lung diseases. Am. J. Respir. Cell Mol. Biol. 20:53-60.

20. Harrison, J.H., Jr., Hoyt, D.G., and Lazo, J.S. 1989. Acute pulmonary toxicity of bleomycin: DNA scission and matrix protein mRNA levels in bleomycin-sensitive and -resistant strains of mice. Mol. Pharmacol. 36:231-238.
21. Omar, T., Geraldine, P., Belehradek, J., and Luis, M. 1993. Bleomycin, an apoptosis-mimetic drug that induces two types of cell death depending on the number of molecules internalized. Cancer Res. 53:5462-5469.

22. Margalet, V., Lucus, M., Solano, F., and Goberna, R. 1993. Sensitivity of insulin-secreting RIN m5F cells to undergoing apoptosis by the protein kinase C inhibitor Staurosporine. Exp. Cell Res. 209:160-163.

23. Hagimoto, N., Kuwano, K., Nomoto, Y., Kunitake, R., and Hara, N. 1997. Apoptosis and expression of Fas/Fas ligand mRNA in bleomycin-induced pulmonary fibrosis in mice. Am. J. Respir. Cell Mol. Biol. 16:91-101.

24. Hagimoto, N., et al. 1997. Induction of apoptosis and pulmonary fibrosis in mice in response to ligation of Fas antigen. Am. J. Respir. Cell Mol. Biol. 17:272-278.

25. Nagata, S., and Suda, T. 1995. Fas and Fas ligand: lpr and gld mutations. Immunol. Today. 16:39-43.

26. Suda, T., and Nagata, S. 1994. Purification and characterization of the Fas-ligand that induces apoptosis. J. Exp. Med. 179:873-879.

27. Miwa, K., et al. Caspase 1-dependent IL-1 $\beta$ release and inflammation induced by the apoptosis inducer Fas ligand. Nat. Med. 4:1287-1292.

28. Woessner, J.F. 1961. The determination of hydroxyproline in tissue and protein samples containing small proportions of this amino acid. Arch. Biochem. Biophys. 93:440-447.

29. Takahashi, T., et al. 1994. Human Fas ligand: gene structure, chromosomal location and species specificity. Int. Immunol. 6:1567-1574.

30. Seino, K., Kayagaki, N., Okumura, K., and Yagita, H. 1997. Antitumor effect of locally produced CD95 ligand. Nat. Med. 3:165-170.

31. Abreu-Martin, M.T., Vidrich, A., Lynch, D.H., and Targan, S.R. 1995. Divergent induction of apoptosis and IL- 8 secretion in HT-29 cells in response to TNF- $\alpha$ and ligation of Fas antigen. J. Immunol. 155:4147-4154.

32. Roth, J.B., Murphy, E.D., and Eicher, E.M. 1984. A new mutation, gld, that produces lymphoproliferation and autoimmunity in $\mathrm{C} 3 \mathrm{H} / \mathrm{HeJ}$ mice. J. Exp. Med. 159:1-20.

33. Waldner, H., Sobel, R.A., Howard, E., and Kuchroo, V.K. 1997. Fas-and FasL-deficient mice are resistant to induction of autoimmune encephalomyelitis. J. Immunol. 159:3100-3103.

34. Sabelko, K.A., et al. 1997. Fas and Fas ligand enhance the pathogenesis of experimental allergic encephalomyelitis, but are not essential for immune privilege in the central nervous system. J. Immunol. 159:30396-3099.

35. Braun, M.Y., et al. 1996. Cytotoxic T cells deficient in both functional Fas ligand and perforin show residual cytotoxic activity yet lose their capacity to induce lethal acute graft-versus-host disease. J. Exp. Med. 183:657-661.

36. Baker, M., Altman, N.H., Podack, E.R., and Levy, R.B. 1996. The role of cell-mediated cytotoxicity in acute GVHD after MHC-matched allogeneic bone marrow transplantation in mice. J. Exp. Med. 183:2645-2656. 